\author{
José Sierra Álvarez \\ Departamento de Geografía, Urbanismo y Ordenación del Territorio. Universidad de Cantabria \\ Grupo de Investigación en Geografía Histórica de los Espacios Rurales
}

\title{
Dos notas de geografía histórica apoyadas en fotografía aérea
}

\section{RESUMEN}

Se presentan aquí dos breves pesquisas de geografía histórica apoyadas en el uso combinado de fuentes de archivo, de trabajo de campo y de fotografía aérea secuenciada. Una, centrada en el tramo alto del río Besaya, trata sobre la evolución del poblamiento en relación con las transformaciones de las vías de comunicación desde el siglo XVIII hasta la actualidad. La otra investigación formula, en el escenario del valle de Cabezón de la Sal, una hipótesis regresiva acerca de la configuración de un sistema hidráulico-molinar desde el siglo XVIII hacia atrás.

\section{RÉSUMÉ}

Deux notes de Géographie historique à partir de photographie aérienne.- Nous présentons ici deux brèves enquêtes de géographie historique à partir de photographie qui s'appuient sur l'utilisation combinée des sources d'archive, de travail de terrain et de photographie aérienne séquencée. L'une, axée sur le cours supérieur de la Besaya, traite de l'évolution du peuplement en rapport avec les transformations des voies de communication du XVIII ${ }^{\text {ème }}$ siècle à nos jours. L'autre enquête, localisée dans la vallée de Cabezón de la Sal, formule une hypothèse

$S^{\prime}$ e presentan aquí dos cortas pesquisas que, además de referirse a espacios de Cantabria, tienen en común el uso comparado de fotogramas aéreos verticales de distintas fechas (además, claro, de otras fuentes de información) y que se insertan expresamente en el campo de la geografía histórica. Una y otra, sin embargo, obedecen

\footnotetext{
${ }^{1}$ Este artículo forma parte de los resultados del proyecto de investigación Diseño de un sistema de localización de fotografías aéreas históricas (España). Aplicaciones a la docencia, la investigación, el planeamiento, la ordenación del territorio y los estudios de paisaje (cso2012-32428), financiado por el Ministerio de Economía y Competitividad.
}

régressive sur la configuration, dès le XVIII ${ }^{\text {ème }}$ siècle, d'un système hydraulique d'origine médieval.

\section{Abstract}

Two notes of historical geography supported by aerial photography.- In this paper, we present two small searches of historical geography which are supported by the combined use of archive sources, field work and sequencial images of aerial photography. One of this is located on the upper valley of Besaya river, and it studies settlement evolution related with the changes of communications network from xvinth century until now. The other search, located on the Cabezón de la Sal valley, set out a regressive hypothesis about the evolution of a medieval hydraulic system.

\section{Palabras clave/Mots clé/Keywords}

Geografía histórica, poblamiento rural, sistema hidráulico, Cantabria (España).

Géographie historique, peuplement rural, système hydraulique, Cantabria (Espagne).

Historical geography, rural settlement, hydraulic system, Cantabria (Spain).

a motivaciones y aproximaciones diferentes. La primera es el resultado de un mero ejercicio docente y mostrativo, en el marco de un programa de postgrado ${ }^{2}$, mientras que la segunda, por su parte, constituye el avance de una investigación en curso apoyada sobre todo en documentación de archivo, pero en la que el uso de la fotografía

\footnotetext{
2 En la asignatura-taller titulada «La dinámica natural y socioeconómica en la montaña cantábrica» del máster Recursos territoriales y estrategias de ordena ción, edición de 2014-2015.
} 
aérea histórica adquiere un papel específicamente argumentativo ${ }^{3}$. Por lo demás, si en la primera el enfoque es principalmente progresivo, dando cuenta de los cambios inducidos por las redes de transporte en la organización del poblamiento desde mediados del siglo XIX hacia la actualidad, la segunda ensaya una aproximación regresiva, formulando hipótesis hacia atrás a partir de la situación de un sistema hidráulico a mediados del siglo XVIII. En cualquier caso, ninguna de ambas pesquisas se habría hecho posible sin la disponibilidad de los fondos identificados y catalogados en el marco del proyecto de investigación titulado Diseño de un sistema de localización de fotografías aéreas históricas (Sigfah) ${ }^{4}$.

\section{CAMINOS Y TRANSFORMACIÓN DEL POBLAMIENTO EN EL ALTO BESAYA}

Es asunto conocido que, a partir de la segunda mitad del siglo XVIII, el valle del Besaya habrá de constituirse en un caracterizado corredor comunicacional (e industrial) en el que, a las vías supracomarcales existentes con anterioridad, de épocas romana y medieval, vendrán a superponerse otras que, como el camino real setecentista, la carretera y el ferrocarril de la segunda mitad del XIX y la autovía de comienzos del xxi, habrán de prestar a la comarca una acusada especificidad en el conjunto de Cantabria (Ansola y Sierra, 2007). Menos conocidos son los procesos desencadenados por esa secuencia de vías de comunicación sobre la red de asentamientos de cada momento y sobre la organización interna de éstos. Se presentan aquí algunos materiales gráficos que pretenden identificar algunos de esos procesos en el tramo alto del corredor.

De la forma en que el camino medieval (la llamada «calzada romana») pudiese haber influido en materia de poblamiento, poco es lo que podemos aventurar. Su traza misma en este tramo del valle resulta hipotética. Sabemos, eso sí, que, en lugar de salvar el desnivel correspondiente a la hoz de Bárcena por el fondo del valle (Hernández, 1941), lo hacía por la vertiente izquierda, dejando al este el núcleo de Lantueno, tocando tangencialmente al de Santiurde de Reinosa, dejando al oeste la villa de Rioseco, pasando al lado de la ermita de San Roque, descendiendo muy rápidamente hacia Pesquera a través

\footnotetext{
${ }^{3}$ Se trata de una investigación aún no cerrada, que se realiza en colaboración con Francisco González Rebanal.

${ }^{4}$ Ministerio de Economía y Competitividad, 2013-2015; investigador principal: Felipe Fernández García (Universidad de Oviedo).
}

del paraje denominado Los Callejones y ascendiendo de nuevo hasta Somaconcha para, desde allí, descender por Mediaconcha hasta Pie de Concha, Cobejo y Villordún, al final de la hoz (tramo, este último, en que se conservan largos lienzos de empedrado y huellas de carros bien visibles). La propia disposición alargada de los núcleos de Media Concha, de Pie de Concha y de Cobejo indica a las claras su vinculación con el camino, así como su probable condición secundaria respecto de él (Ansola y Sierra, 2007, p. 31). Menos evidente resulta, en cambio, la relación entre camino y núcleo en el caso de Santiurde (Fig. 1). El camino, como se apuntaba, alcanzaba al caserío por su borde oriental, tocando a la ermita del Buen Suceso y dejando a su derecha la iglesia parroquial, en posición excéntrica respecto del núcleo. Hasta allí, el camino llegaba seguramente a través del luego llamado «de Cabezones al pueblo» (catastro de 1957); pero inmediatamente después de salvar el caudaloso barranco de Santiurde (o de Albardón), allí en donde habría de instalarse una fábrica de harinas hacia 1871, el viejo camino parece haber configurado un diminuto barrio significativamente denominado La Venta Vieja (o seguramente, sin más, La Venta), con mención documental de al menos 1578 (Ansola y Sierra, 2007, p. 33).

Por su parte, el camino real de la segunda mitad del siglo XVIII, al optar por la vertiente derecha de la hoz de Bárcena, vendría a reorganizar muy significativamente el poblamiento de la zona, un proceso que habría de verse intensificado con la carretera del siglo XIX, coincidente en parte con el trazado del camino borbónico y, en otros tramos, enteramente divergente de él, especialmente en la hoz misma, con una decidida opción por una traza de fondo de valle. Esa reorganización hubo de adoptar distintas modalidades. En unos casos, significaría el inicio de la despoblación de algunos núcleos, como Somaconcha, Mediaconcha o, más abajo, Villordún (García Alonso, 1994); y en otros, la geminación de los núcleos preexistentes, con la aparición de barrios enteramente ex novo al borde mismo de las nuevas vías. Es el caso, desde luego, del barrio de la Carretera en Lantueno o del de La Venta Nueva en Santiurde (Fig. 1), pero también, más abajo, el del Ventorrillo en Pesquera o el del Mesón en Santa Olalla, por no mencionar más que los del tramo alto del valle ${ }^{5}$. Además, algunos barrios muy específicos

\footnotetext{
${ }^{5}$ Las dos imágenes de la Fig. 1 proceden del Archivo Histórico del Centro Geográfico del Ejército, Memoria del Ytinerario de Canduela á Peñacastillo 1858, C-28, núm. 10. (una extraordinaria fuente documental que reúne felizmente informaciones muy precisas bajo forma textual y cartográfica, aunque, en este último caso, la imprecisión geodésica no favorece precisamente las comparaciones
} 
de nueva creación no se explican si no es en relación, por más que mediada, con las nuevas vías. Es el caso de aquellos que surgen en los siglos XVIII y xIX en el inmediato entorno de algunas instalaciones industriales cuya estrategia de localización se apoyaba, entre otras cosas, en la proximidad a las nuevas vías y a la energía hidráulica del propio Besaya. Tal es el origen del pequeñísimo barrio de la Venta en término de Aldueso (en torno a una venta y una fábrica de harinas de establecimiento anterior a 1839), de La Ferrería en Santiurde (transformada en harinera a comienzos de los años setenta del siglo XIX) o, aguas abajo, del Ventorrillo en Pesquera (en relación con una venta, ya lo sabemos, pero también de dos fábricas de harina, una de 1801 y otra de en torno a 1920), del barrio de la fábrica de harinas de Bárcena de Pie de Concha (de 1796), del barrio de Portolín en Molledo (en torno a una ferrería, transformada en harinera hacia 1845 y en fábrica de hilados a muy comienzos del siglo xx), de la fábrica de harinas de La Inesuca en La Serna (establecida en 1796) o del de las Bárcenas en Las Caldas (en torno a una ferrería de hacia 1750 y, casi al tiempo, de una harinera de 1785), por no hablar del propio núcleo de Los Corrales de Buelna (Ansola y Sierra, 2007, passim).

En comparación con el camino dieciochesco o la carretera del siglo XIX, la capacidad reorganizadora del ferrocarril en materia de poblamiento queda muy desdibujada. No puede caber duda de su trascendencia por lo que hace al crecimiento físico y poblacional de los núcleos a pie de los raíles (que, por lo demás, resulta indiscernible de los efectos inducidos al respecto por las propias vías camineras); pero, desde una perspectiva estructural, parece haberse limitado (al menos en el tramo alto del valle) al barrio de la Estación en Bárcena de Pie de Concha e, indirectamente, al constituido en el entorno del establecimiento lácteo de Collantes. Por su parte, nada parece haber incidido el ferrocarril en el caso de Lantueno, en el que la traza ferroviaria describe un gran arco que evita al núcleo, ni tampoco en el de Santiurde, en donde la existencia de apeadero no ha bastado para la formación de barrio alguno ${ }^{6}$. Núcleo ex novo, aunque efímero, sí llegó a formarse en el paraje conocido como

topográficas de detalle) y de Archivo del Instituto Geográfico Nacional, Planos de población y, en algún caso, cuadernos de topógrafo (sin que nos sea dado saber por qué, el plano de población de Santiurde recoge únicamente el caserío del barrio principal, pero no el de la Venta Vieja, el de la Venta Nueva y el de la Ferrería).

${ }^{6}$ Las fuentes para la Fig. 2 son el vuelo de 1953 para la formación del catastro (<http://cartografia.cantabria.es > y Departamento de Geografía, Urbanismo y Ordenación del Territorio, Universidad de Cantabria), y el vuelo de 2007 del PNOA (<http://cartografia.cantabria.es>).
La Casa del Río, no lejos de Bárcena de Pie de Concha y en el fondo del valle del Bisueña. Se trata de un poblado destinado al alojamiento de los muchos trabajadores foráneos ocupados entre 1862 y 1866 en los formidables trabajos de las rampas de Bárcena. Las ruinas existentes hoy dan testimonio de la envergadura (Fig. 2) y, hasta cierto punto al menos, de las pobres tipologías constructivas que alojaron entonces a nuestros navvies (García Alonso, 1994).

Por su parte, la evolución reciente de la estructura del poblamiento no parece tener relación con las vías de comunicación. No, desde luego, en lo que hace a las variantes de la carretera que, en el último tercio del siglo $\mathrm{xx}$, evitaban el paso por el centro de algunos núcleos, y tampoco por lo que se refiere a la autovía de comienzos del xxI, ni siquiera (al menos por el momento) en el entorno de las conexiones de ésta con la carretera. Los cambios observables (Fig. 1) remiten más bien a procesos de otro orden, bien conocidos: al macizamiento de los alveolos intersticiales de los caseríos y a una dispersión secundaria intercalar de establecimientos ganaderos y de equipamientos públicos.

\section{RIBERAS FLUVIALES E INGENIOS HIDRÁULICOS EN EL BAJO SAJA}

A mediados del siglo xviII, el Catastro de Ensenada daba cuenta de nueve molinos corrientes y molientes en los concejos Cos (con su barrio de Cintul) y de Mazcuerras (con sus barrios de Coíño, Santa Gadea y Villanueva), todos ellos en la ribera izquierda del río Saja. De ellos, ocho molían con aguas derivadas del caudal principal a través de un único azud, que las sangraba a la altura de la hoz de Santa Lucía y las devolvía a su madre inmediatamente antes del breve estrecho de La Peña. Los casi seis kilómetros de ese caz o calcera constituían, pues, un gran sistema hidráulico unificado, una suerte de rosario de ocho cuentas enlazadas por un solo hilo de agua. No se trata en modo alguno de un fenómeno único en la España del norte (baste pensar en el sistema del Sajón, justamente en la margen izquierda del Saja en ese mismo tramo), pero sí muy poco frecuente, especialmente por la extraordinaria longitud de la calcera y por su proximidad al lecho principal. Esta última circunstancia no deja de resultar sorprendente dadas las difíciles condiciones de instalación de ingenios hidráulicos en unas riberas muy movedizas. Porque en ese tramo, el lecho del Saja se configura como un trenzado de hilos de agua y cauces abandonados, que dan testimonio de una atormentada historia 


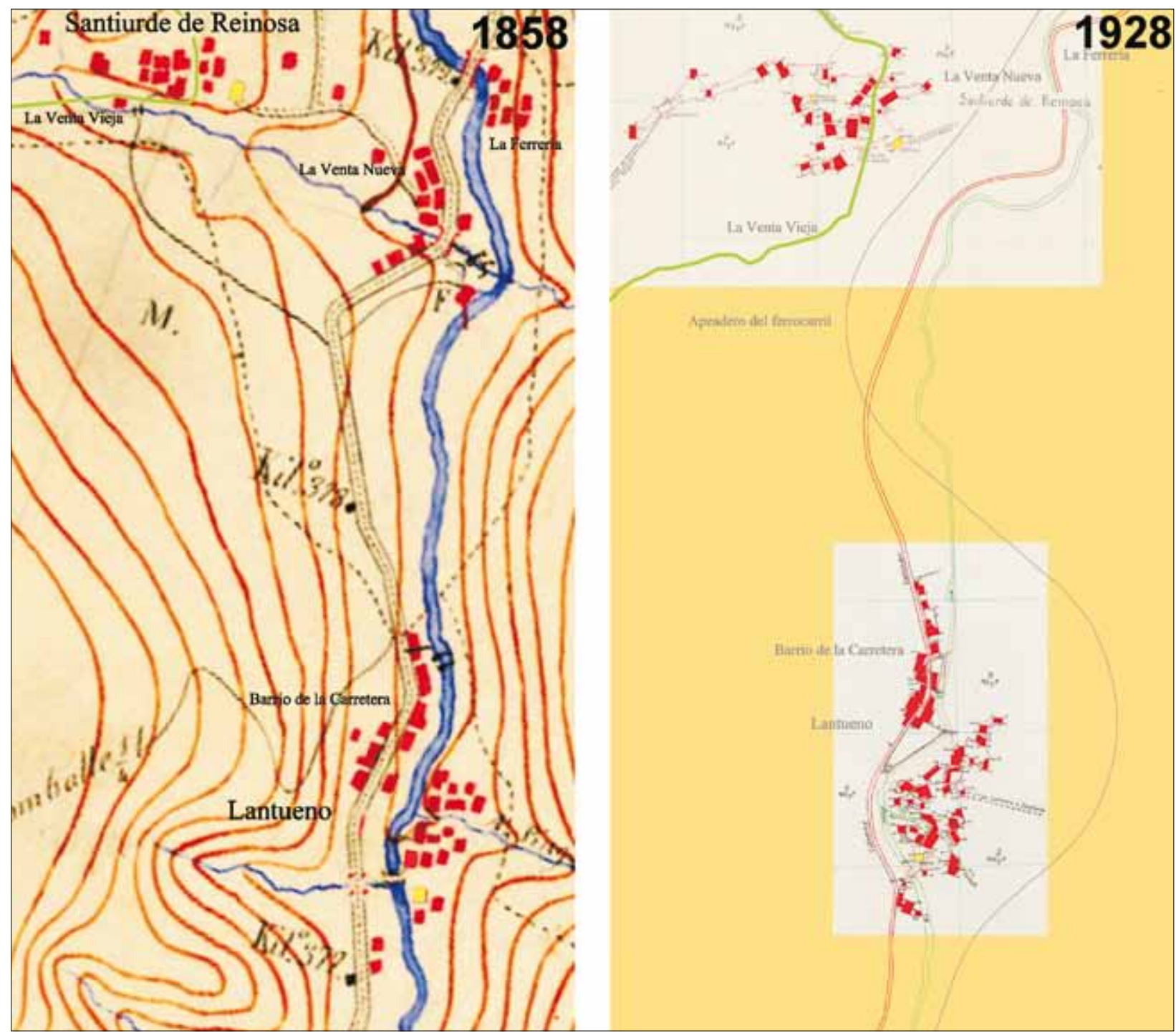

FIG. 1. Lantueno y Santiurde, 1858, 1928, 1953 y 2007.

morfológica. La estrecha imbricación de paleocauces y arenales (o leras, en denominación local) y el trazado divagante del lecho del río (Fig. 3) ${ }^{7}$ parecen estar en relación con las específicas características del régimen hidrológico del Saja (esencialmente pluvial, con máximos principales de caudal en diciembre y enero, y secundario en abril), pero también con los elevados desniveles que ha de salvar su curso medio y alto, con la escasa jerar-

\footnotetext{
${ }^{7}$ En el mapa aparecen representados nueve ingenios (y no los ocho existentes a mediados del siglo XVIII). Entre los molinos de Arriba y de Abajo de Cos, se añadió al sistema una fábrica de luz en los años veinte del siglo xx.
}

quización de su red y, a otra escala, con la escasa capacidad de transporte de materiales de que el flujo adolece al alcanzar las arcillas del diapiro de Cabezón. En tales condiciones, las riberas del Saja en ese tramo debieron de verse sometidas a un largo y sostenido proceso en el que los fenómenos constructivos se articulaban íntimamente con otros, súbitos, de naturaleza destructiva. Las riberas del Saja en el valle de Cabezón fueron modeladas, en suma, a golpe de avenidas o, en denominación popular, llenas (Ureña, 1999, passim; García Codrón y Garmendia Pedraja, 2003; Delgado, 2004).

Son muchas, en efecto, aquellas de las que el valle guarda memoria, desde las de la primera mitad del si- 


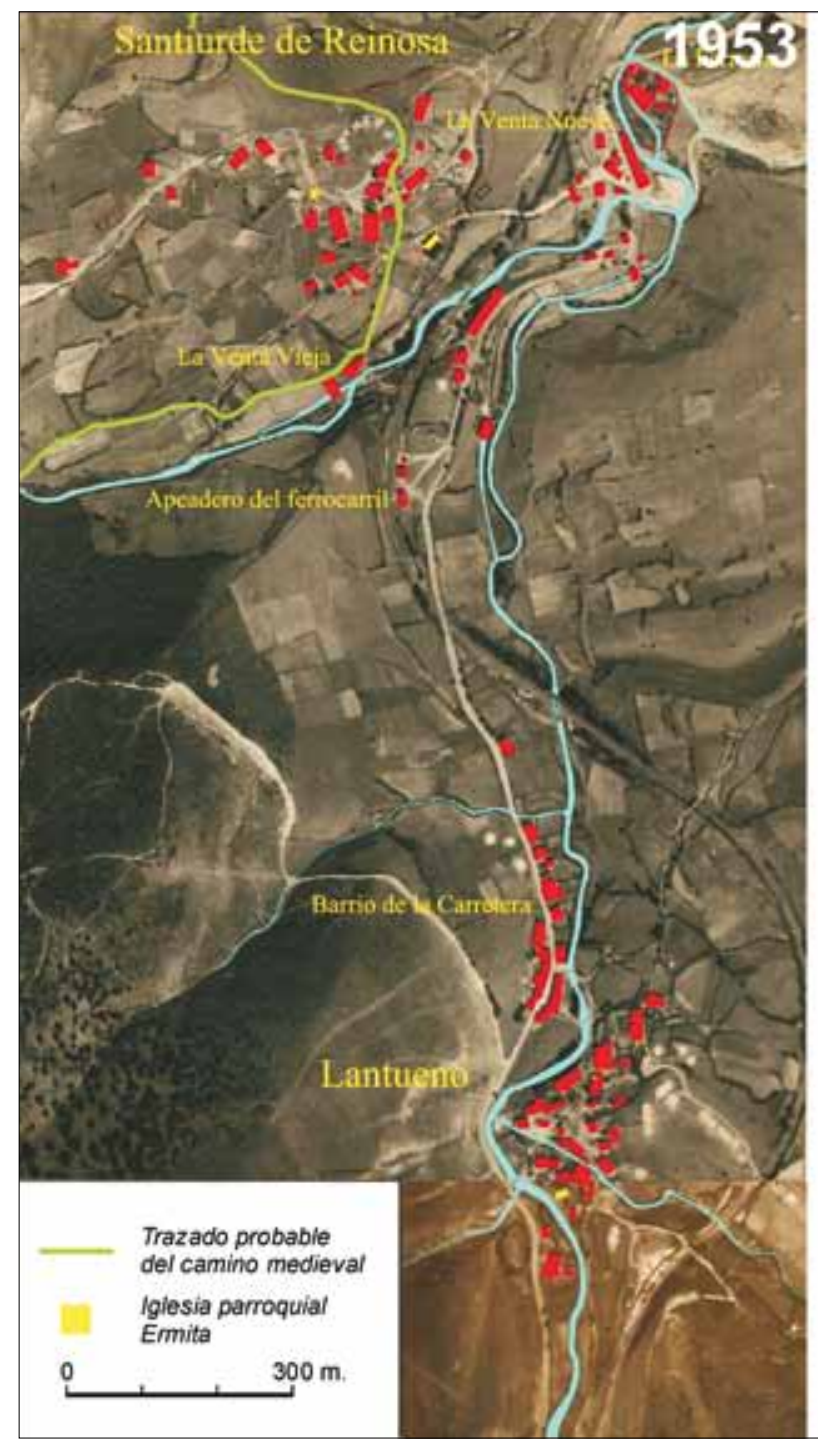

glo Xvi (la de, por ejemplo, junio de 1540, que habría arrasado casas, campos y molinos, e inundado el pozo de la sal), hasta las de los últimos años, pasando por la devastadora de agosto de 1834, que «había destruido el puente de Santa Lucía, y todos los demás de madera que existían, quedando incomunicadas una gran parte del año, no solo las dos mitades de la población del antiguo valle de Cabezón de la Sal, sino la oriental y occidental de esta Provincia» ${ }^{8}$. De otras muchas avenidas nada nos

${ }^{8}$ Archivo Histórico Provincial de Cantabria, Diputación, Obras Públicas, leg. 6-2. Una cierta relación de avenidas puede construirse a partir de las noticias de Vara (1995, passim) y García Codrón (2003, pp. 63-65), además de las informaciones que irán apareciendo en este mismo trabajo.

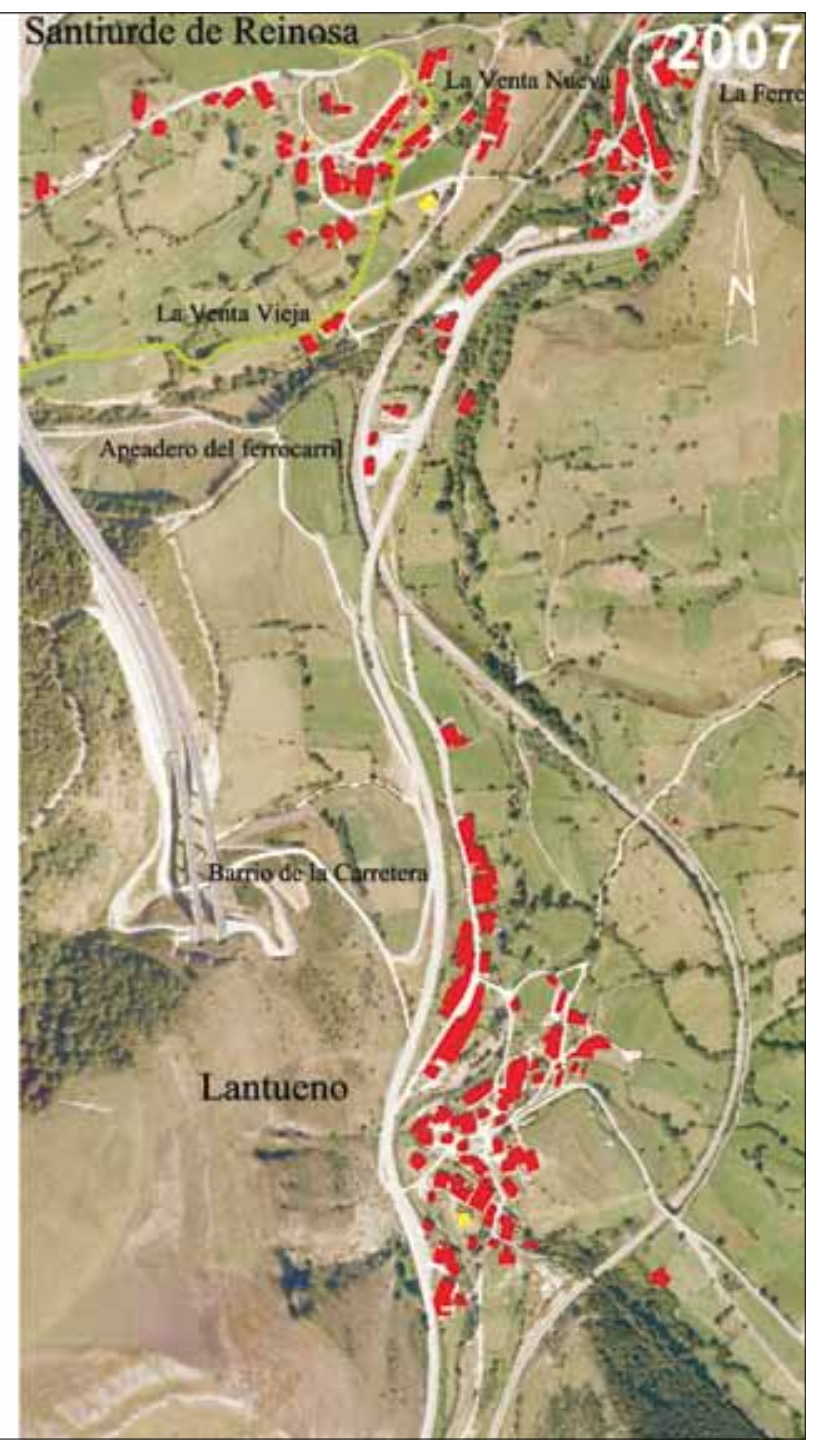

es dado saber, al menos sin un rastreo sistemático de documentación o sin una pesquisa estratigráfica específica que haga aflorar lo mucho que al respecto guardan en silencio los aluviones y paleocauces de las riberas del Saja.

Como en otros lugares, esa inestabilidad estructural parece haber configurado en el pasado toda una larga y tenaz cultura campesina de defensa frente al exceso episódico de agua y, en relación con él, de protección de las riberas. Hasta donde nos es dado saber, esa cultura no se apoyaba (al menos en la Edad Moderna) en la unidad territorial del valle, sino en los marcos normativos de los diversos concejos ribereños. Eso explica la abundancia y reiteración de los conflictos hidráulicos entre ellos, fuese en materia de atribución de responsabilidades en 


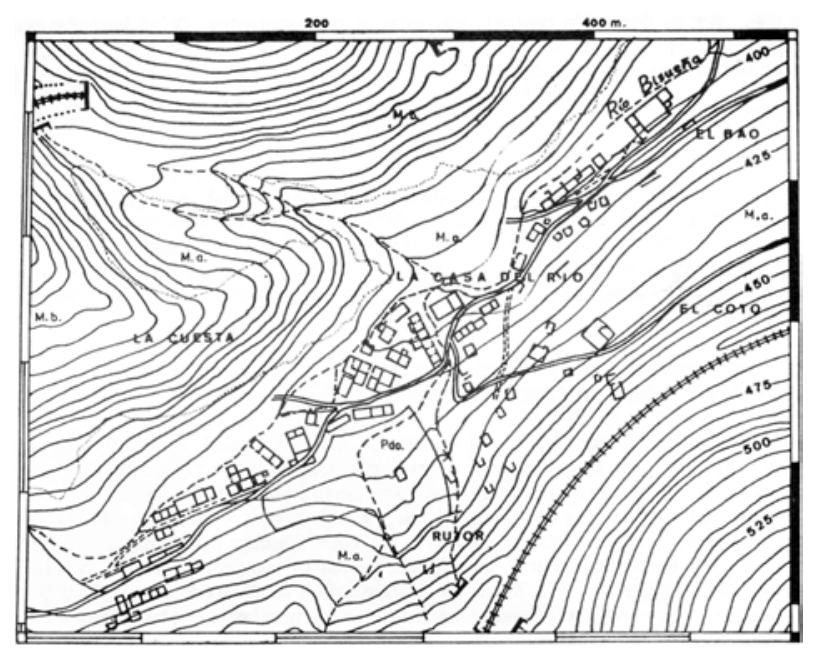

FIG. 2. El poblado ferroviario de La Casa del Río. Tomado de García Alonso, 1994.

los destrozos de las avenidas, o fuese en relación con las obras necesarias para captar el agua destinada a los ingenios de molienda de cereal. La gestión supracomunitaria del agua quedaba reducida así a la vía judicial o, en todo caso, a las concordias entre concejos. Las ordenanzas de éstos recogían sistemáticamente las prescripciones en la materia, fuese mediante la vigilancia de las riberas, fuese mediante la conservación de la vegetación ribereña o fuese mediante la reconstrucción de presas y defensas9. También lo hacían las respuestas de los concejos al interrogatorio de Ensenada. Cos, por ejemplo, con cincuenta vecinos, «se ocupa en el reparo de las [...] presas para detener las abenidas a fin de que no se aneguen y destruyan los prados y mieses de este pueblo ocho días cada un año». El de Mazcuerras, con más vecinos (214) y mucha más línea de ribera, era más explícito: el concejo, en efecto, «se ocupa en los reparos de la Rivera del Rio Saxa, treinta dias cada año en los meses de agosto y septiembre, para livertar las haciendas de las abenidas de dicho Rio» (frente a sólo tres días «en la composicion de las carreteras conzejiles»), además de gastarse cada año ochocientos reales «en composizion de comportas de dicho Rio». Por su parte, el concejo de Ontoria-Vernejo, con una ribera igualmente muy dilatada, se limitaba a mencionar «cupos de puentes y muelles» ${ }^{10}$.

\footnotetext{
${ }^{9}$ Las ordenanzas que manejamos son las de Vernejo-Ontoria (1770), Mazcuerras (1770) y Cos (1817). Como es habitual, se trata de textos refundidos a partir de ordenanzas de fechas anteriores.

${ }^{10}$ Portal de Archivos Españoles (Pares), Catastro de Ensenada, Respuestas Generales.
}

Más allá de la normativa, son los conflictos entre concejos los que nos permiten atisbar con más detalle (y, desde luego, mucha más complejidad) algunos de los rasgos de esa cultura del agua. El más antiguo del que disponemos es de 1622, aunque, como veremos, aporta información de un siglo antes. Todo parece iniciarse en noviembre de ese año, con la denuncia que Cos y Mazcuerras presentaban contra Ontoria-Vernejo ante la justicia del valle, encarnada en este caso en la persona del juez Marquelayn. Al parecer, el concejo de la ribera izquierda habría construido «una presa muy grande en el Varocal del [es decir, del dicho concejo de OntoriaVernejo] en que hechavan el Rio caudal de Saxa hacia la parte de dicho conzejo de mazquerras», con los perjuicios consiguientes. Ontoria-Vernejo replicaba que habían sido más bien los vecinos de Cos y Mazcuerras los que, con anterioridad, habían «atravesado ciertas presas en el Rio de Saxa en el sitio que llaman cardiel [aguas abajo del primer punto] y otros sitios» (así el concejo de Mazcuerras en el sitio de Sajuca, «frontero del prado nuevo de $\cos »)$, impidiendo «seguir el dicho Rio la madre antigua», por lo que Ontoria-Vernejo se había limitado a construir la presa «para defensa de su rivera [...], para que el dicho rio no se metiese en los concejos como se meteria si biniera otra llena», pues, si así fuese, «les llevaria sus casas y moliendas [y] prados y heredades [...y] causaria el despoblamiento de los dichos lugares», como ya había ocurrido, pues «con las grandes abenidas y dilubios de aguas que avia avido los dias pasados[,] el Rio de Saja avia salidose de madre y corriente ordinaria y natural y se avia entrado e rompido por muchos prados y heredades de sus partes [es decir, del concejo de OntoriaVernejo...] y avia estado a punto de entrarse por el propio lugar y anegarle». Alegaban además que, si no se ponía remedio a la intervención de Cos y Mazcuerras, lo peor estaba por llegar con el invierno, «que era cuando muy de ordinario benian las avenidas y crecidas de aguas».

Atrapado en su propia obra de Cardiel, el concejo de Mazcuerras argumentaba con razones de orden general, relativas al propio régimen hidrológico del río:

El dicho rio de Saja a movido su alveo y principal corriente muchas beces y avia subcedido muy de ordinario avido roturas e llevado prados y heredades y averes en mucha cantidad ansi del dicho concejo de mazquerras como del de ontoria[,] y juntadose a los dichos concejos quando al uno quando al otro [...] y los prados [y] eredades de cada un concejo an estado sujetos a las avenidas y alubiones del dicho rio sin mas escepcion.

A la altura de 1629 , Cos, por su parte, aludía a una concordia de 1522, alcanzada al parecer tras una gran 


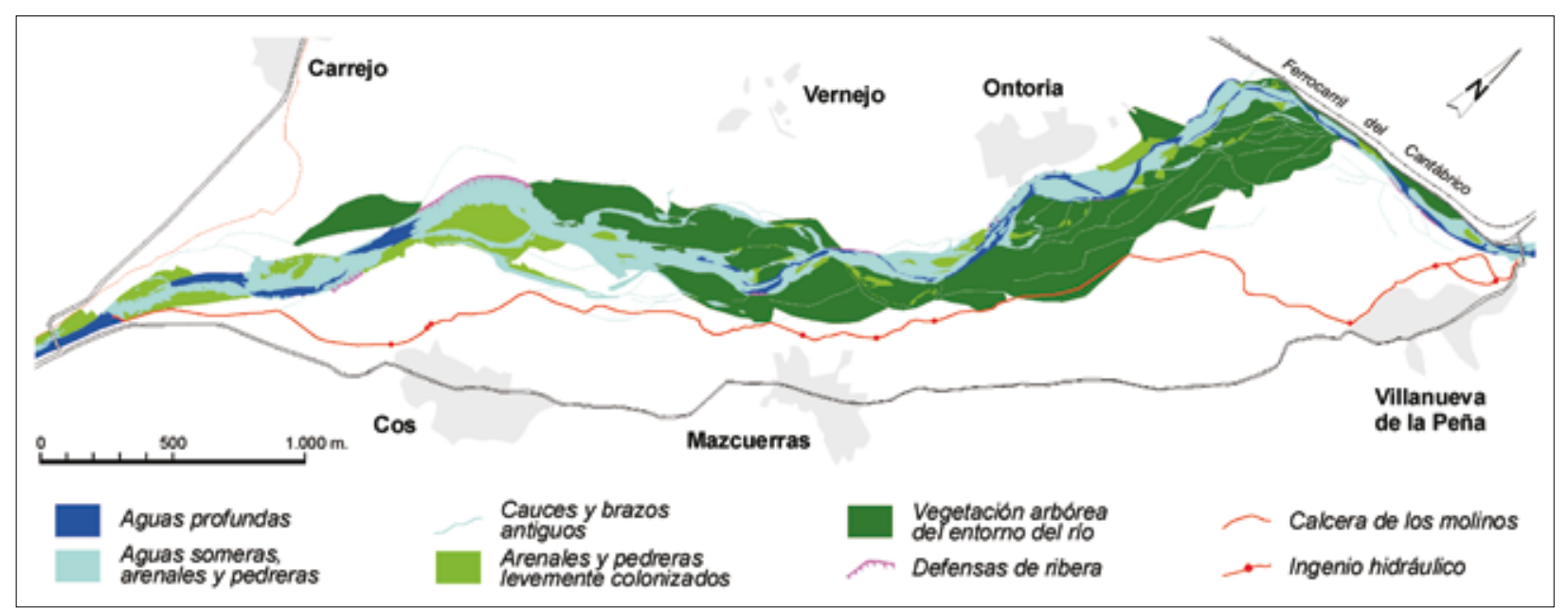

FIG. 3. El lecho del Saja en el valle de Cabezón de la Sal, 1953. Elaboración propia a partir del vuelo de 1953 para la formación del catastro.

avenida (con desgracias de «niños y personas» que iban a los molinos) en la que «el rio corria tal que se divirtiese [y] rompiese las riberas como lo avia echo muchas bezes y particularmente desde el año de [mil quinientos] veinte y uno», en las primeras fases de la pequeña Edad del Hielo. Al parecer, la tal concordia (en otro lugar, sentencia) amparaba su derecho «de poder fortalecer sus riberas con piedras céspedes y otros baluartes que les combiniese no lo atravesando todo el dicho rio», como habría hecho Ontoria-Vernejo en su presa del Varocal, origen de toda la disputa.

En 1632, el pleito, finalmente, se zanjaba temporalmente por medio de una nueva concordia entre hombres buenos de todas las partes, a fin de evitar los subidos gastos de continuarlo en la Real Chancillería de Valladolid. Establecía las reglas para el futuro, pero, al tiempo, nos suministra una imagen del estado de las cosas en ese momento. Con candoroso optimismo, afirmaba el derecho de Ontoria-Vernejo a «fortificar mantener e sostener ahora y en todo tiempo del mundo» la presa de Sajuca «desde la mitad de la madre del rio a la parte del dicho concejo de ontoria». Por otro lado, obligaba a Mazcuerras a desarmar «otra presa [o, en otro lugar, «morio»] que esta frontera a la [...] suya dentro del prado nuevo de la granja de cos», así como a retirar «una presa que esta en el sitio y puesto de [...] bega de coiño». Fijaba además la línea de ribera de la margen izquierda: desde la presa de Sajuca, correría hasta la desembocadura de «la calcera de los molinos de dicho concejo de ontoria e bernejo», continuaría por El Alsar «asta llegar a[1] lomo y presa que llaman de marquelain» (es decir, la que, tomando el nombre del juez que había decretado su embargo, había dado inicio al pleito) y por «el bardal de la barca». Desde esa línea, la concordia establecía que «a de tener el dicho rio de anchura y gueco y madre propia cincuenta y ocho codos [...] para el alveo y corriente del dicho rio». En las riberas así fijadas, y «desde la dicha venta de santa lucia asta el dicho escobio de villanueva[,] cada qual de dichos concejos todos y qualquiera de ellos puedan reparar y reparen su rivera como mas le combenga guardando la madre antigua y señalada en esta concordia». Los tres, además, se comprometían a no levantar en el futuro «presa canal ni otro ympedimento alguno que embarace[,] perjudique ni estorbe el corriente», a derribar «las presas viejas y demas impedimentos de alisas y otras cosas»y, «en quanto a los arboles[,] leña y madera [y] piedra [... que trae el dicho rio con sus abenidas y crecientes [,] cada un concejo acuda a quitar la mitad de ello [es decir, en el ancho de 29 codos] e reparar su rivera con ello» ${ }^{11}$.

Especialmente en las argumentaciones de las partes, la ejecutoria evidencia un notable conocimiento del régimen del Saja, así como de sus fenómenos excepcionales; pero nos informa igualmente de algunos aspectos tecnológicos de la ingeniería hidráulica campesina, empezando por las denominaciones mismas empleadas para designar las obras de defensa de riberas («presa», «edificio», «fortaleça», «presa estacada fortaleça», «presas e murallas», «presa e baluartes», pero también, ahora en negativo, «cegar» brazos del lecho trenzado) y continuando por un conjunto de indicaciones que permiten atisbar una cierta

\footnotetext{
${ }^{11}$ Archivo de la Real Chancillería de Valladolid, Registro de Ejecutorias, 2577-37.
} 


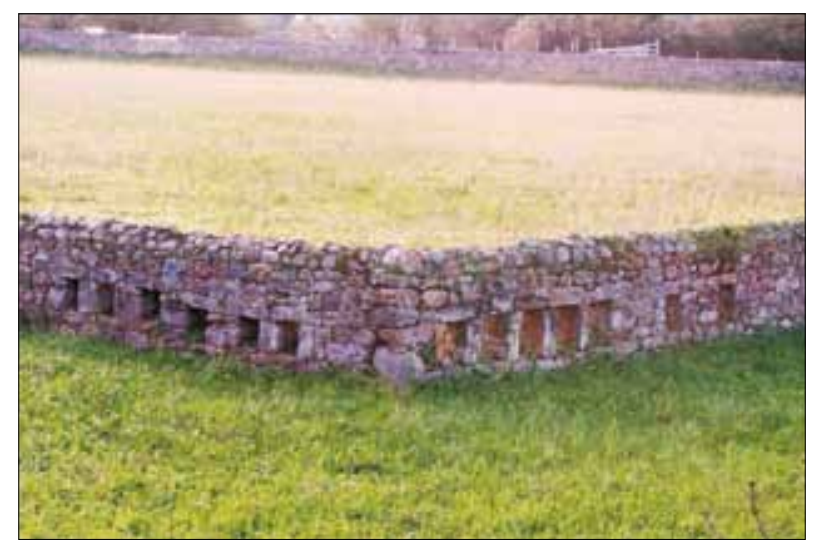

FIG. 4. Defensa de finca en la margen izquierda del Saja, 2002. Fotografía de F. González Rebanal.

tipología de defensas («fortalecer sus riberas con piedras [,] céspedes y otros baluartes», «presa fuerte de piedra», «presa de pyedra», «morio e pared»). Poca herencia toponímica, es verdad, ha legado esa práctica sostenida en el tiempo (¿quizá pudiera serlo la denominación de Fuerte que sirve para nombrar una parcela alargada en territorio de Ontoria-Vernejo, alejada unos 150 metros del lecho actual?); pero no es menos cierto que su herencia material no resulta despreciable si se observa en detalle el lecho pedregoso del Saja en ese tramo en aguas bajas, que permite identificar lo que pudieran ser los restos arrasados de algunas presas, especialmente en los extremos del tramo más conflictivo e inseguro, hoy canalizado. Mucha más herencia han dejado, como cabía esperar, las intervenciones muy posteriores (y seguramente a cargo ya de instituciones supramunicipales) ${ }^{12}$ que se aprecian en la fotografía aérea de 1953 (Fig. 3) y que, a veces muy alejadas del lecho actual, aún se conservan en forma de muros de contención y espigones, ya muy naturalizados por la vegetación ribereña (Figs. 4 y 5).

En esas condiciones de riberas movedizas, bien se entiende que las tres primeras noticias de que disponemos acerca molinos en la ribera derecha (La Puente, Cintul y La Seo), anteriores siempre a la calcera unificada del siglo XVIII, los ubicasen alejados del colector principal, como si las comunidades campesinas quisieran huir en lo posible de los riesgos derivados de la inestabilidad de sus riberas, aun a costa de reducir su capacidad de molienda a los magros e irregulares caudales de alguno de

\footnotetext{
${ }^{12}$ En 1888 , los municipios del valle clamaban por el encauzamiento del río (García Codrón, 2003, pp. 65-67, citando La crisis agrícola y pecuaria, 1888 v, p. 701).
}

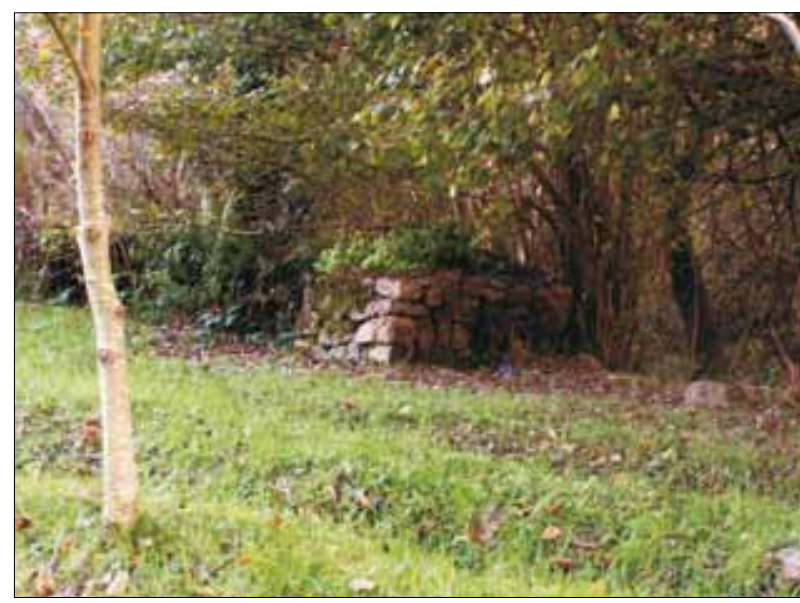

FIG. 5. Defensa de ribera en la margen izquierda del Saja, 2002. Fotografía de F. González Rebanal.

los tres arroyos de curso bajo meandriforme que drenan esa vertiente: el Ronero, el Pulero (o, en la época, Uciebra) y el de la Fuente del Ojo, considerados de oeste a este, y quizá también (por más que no dispongamos de menciones documentales), de algunos otros que, siempre amenazados por las avenidas, moliesen precariamente con aguas del Saja ${ }^{13}$. Esa situación difícilmente habría podido sostenerse a partir de mediados del siglo XVII, cuando la difusión del maíz en el valle desde comienzos de la centuria debió de traer consigo un indudable incremento de las necesidades de molienda de las comunidades campesinas ${ }^{14}$.

Sabemos ya cuál fue la respuesta de los concejos de Cos y de Mazcuerras: el sistema integrado de la calcera de los molinos ${ }^{15}$. Pero desconocemos su génesis funcio-

\footnotetext{
${ }^{13}$ El molino-ferrería medieval de Cintul, centro de un pequeño barrio de Cos con iglesia propia, ha sido objeto de una investigación específica, todavía inédita. Véase J. Sierra Álvarez y F. González Rebanal: El despoblado medieval de Cintul (Mazcuerras, Cantabria), 2014.

${ }^{14}$ Todavía en 1567 , los cultivos presentes en el valle eran la avena, la borona, la escanda y el lino. La primera mención al maíz en Mazcuerras (aunque no enteramente segura) es de 1607; y la enteramente fiable es de 1614. A partir de ese momento, el cereal americano habría experimentado una muy rápida difusión en el valle (Vara, 1995, pp. 21 y 96). En 1616, un vecino de Villanueva estaba «dando de comer a un caballo maíz». Archivo de la Real Chancillería de Valladolid, Registro de Ejecutorias, 2218-37.

${ }^{15}$ La única duda que podría caber al respecto es que, para mediados del siglo XVIII, la calcera unificada de Cos y del núcleo de Mazcuerras no se prolongase aún hasta el barrio de Villanueva y sus molinos. Es verdad que el precario mapa de Tomás López (1774), que ya recoge la calcera unificada hasta aguas abajo del Mazcuerras, la derrama hacia el Saja a la altura de Coíño. Y sin embargo, no es menos verdad la contundente e incontrovertible afirmación del común de Mazcuerras ante los agentes de Ensenada de que «los tres [molinos] de á dos ruedas cada uno, que [...] son propios de el Varrio de Villanueva [...] muelen regularmente siete meses del año con agua del Río Saxa», y no, por tanto, con las
} 


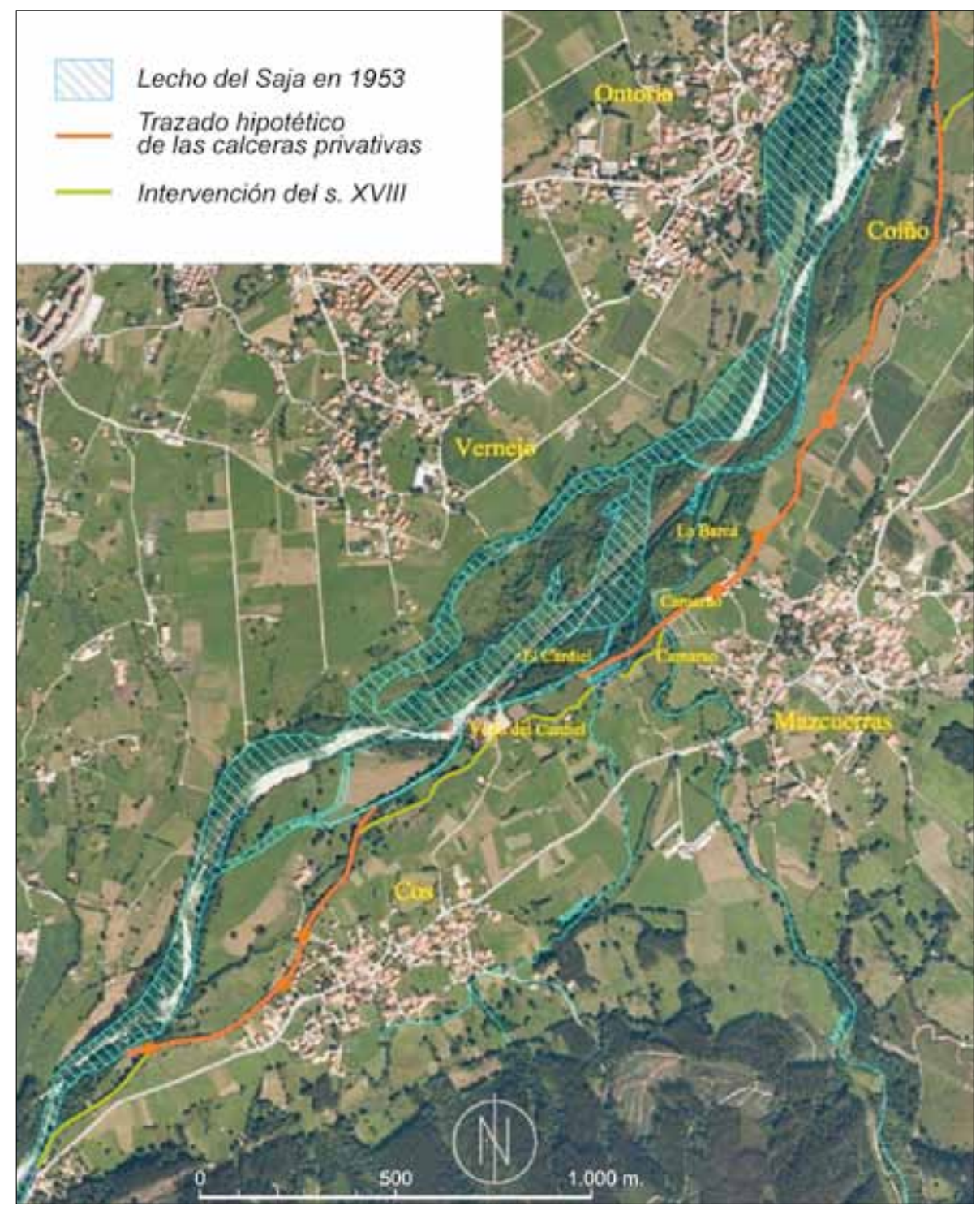

FIG. 6. El lecho del Saja, 1953 y 2007 e hipótesis de formación de la calcera unificada. Elaboración propia a partir del vuelo de 1953 para la formación del catastro y del vuelo PNOA 2007. nal y su cronología precisa. Para fundar una hipótesis al respecto, habremos de leer regresivamente las fuentes de mediados del siglo XVIII. La propia individualización de algunos de ellos (de Arriba y de Abajo, en Cos, y de Abajo en Mazcuerras, lo que sugiere la existencia de otro $\mathrm{u}$ otros aguas arriba) apunta a su funcionamiento en sis-

del arroyo de la Fuente del Ojo. Portal de Archivos Españoles (Pares), Catastro de Ensenada, Respuestas Generales. Para entonces, pues, las aguas corrían por la calcera desde el puente de Santa Lucía hasta La Peña, de hoz a hoz. Por lo demás, unas décadas más tarde, la referencia a «el camarado de el barrio de Coyno» no hace sino confirmar las cosas. Archivo de la Real Chancillería de Valladolid, Registro de Ejecutorias, 3637-49. tema, sobre la base de derivaciones que sostenían a más de un molino. ¿Se trataba ya de una sola calcera, desde Cos hasta La Peña, como sin duda sabemos que lo era en tiempos del Catastro de Ensenada? Las propias informaciones del catastro permiten sostener con verosimilitud que así era, al menos por lo que hace a los molinos de Cos y de Mazcuerras. El último concejo reconocía, en efecto, que tenía obligación escriturada de que una persona de cada casa asistiese dos días al año a obras concejiles en favor de Cos «por haverle dado [Cos] calzera para el conducto del agua a dichos [sus privativos] molinos». ¿Significa eso que la formación de una calcera única venía de mucho tiempo atrás? No lo parece en ab- 


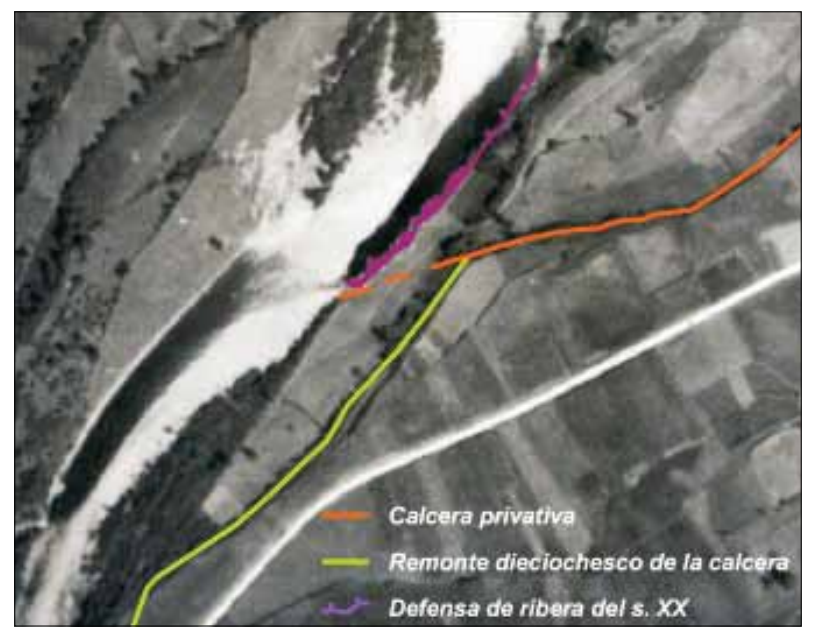

FIG. 7. Hipótesis sobre el inicio de la calcera privativa de Cos. Elaboración propia a partir del vuelo de 1953 para la formación del catastro.

soluto, al menos si se hurga con detalle en la documentación. Así, el concejo de Mazcuerras reconocía entre sus cargas la deuda que tenía desde 1742, por «la hechura de un camarado», con el constructor (o tal vez con un particular que hubiese adelantado los fondos). Y, al respecto, conviene llamar la atención acerca de un pequeño grupo de fincas de Mazcuerras que recibe precisamente esa denominación, la de «Camarao», justamente ubicadas en el arranque del sistema molinar concejil. Reconocía además que debía igualmente la mitad del coste de «la comporta que se haze en comun con el lugar de cos». Todo parece indicar, pues, que la formación de la calzera única (al menos hasta el barrio de Coíño) era entonces asunto reciente. Dicho en otros términos, la suposición lógica más verosímil es que, con anterioridad a mediados del siglo XVIII, cada uno de ambos concejos dispusiese de una calcera privativa, y que, sólo a partir de esa fecha (y, si se quiere, desde el entorno de 1740), la reiteración de viejas disputas irresolubles hubiese conducido a un acuerdo que se habría expresado en la unificación de ambas calceras privativas a partir de una derivación única ${ }^{16}$.

Cuando la documentación no habla con suficiente claridad, habrá que interrogar al terreno. Y lo cierto es que su observación detallada, así como de la fotografía

${ }^{16}$ ¿Tendrá que ver con ello la escueta y expresa referencia a que el concejo de Cos, al menos desde 1747, debía pagar anualmente 29 reales al de Mazcuerras en concepto de «avenenzia de el Pleito de Cardel», sin duda posterior a la sentencia que ya conocemos de 1632, y quizá deuda arrastrada desde entonces? Para todo lo anterior, véase Portal de Archivos Españoles (Pares), Catastro de Ensenada, Respuestas Generales. aérea de 1953 (pero también de la serie A, de mediados de la década anterior), permiten abundar en la hipótesis mencionada (Fig. 6). Seguramente aprovechando algún paleocauce, la vieja calcera de Cos podría haber arrancado del azud que todavía hoy sangra aguas por debajo del viejo puente de Santa Lucía y a la altura de la venta del mismo nombre, y disponerse de acuerdo con su trazado actual. Sin embargo, no deja de extrañar en éste la notable curva hacia el este que experimenta varias decenas de metros aguas abajo, a la altura del punto en que el tramo anterior parece buscar la vecindad del río. Precisamente en ese punto, la fotografía de 1953 permite adivinar en el lecho del Saja en aguas bajas una discontinuidad que bien pudiese corresponderse con un antiguo azud (Fig. 7). ¿Podría tratarse del inicio de la vieja calcera de Cos? Como quiera que haya sido, la calcera privativa seguiría aproximadamente el trazado de la actual en ese tramo para, tras dar servicio a dos molinos (el de Arriba y el de Abajo), devolver aguas a la madre. Pero no, y ello es lo relevante, al cauce principal, sino a un complejo brazo del lecho en su borde meridional, hoy desaparecido (pero no aún en 1953) y que con mucha probabilidad debía de corresponderse con la denominación de Sajuca que ya conocemos.

Por su parte, la hipotética calcera privativa de Mazcuerras resulta de más difícil identificación, tanto documentalmente como sobre el terreno. Por razón funcional, su azud de derivación debía encontrarse aguas abajo de la devolución a la madre de la calcera de Cos: en el crucial y conflictivo paraje del Cardiel, por tanto, y seguramente en algún punto de la prolongación hacia el este del brazo de Sajuca. Tanto desde un punto de vista topográfico como desde una perspectiva funcional, lo más probable es que ese punto se ubicase al oeste del curso del Ronero, a fin de suplementar con su escaso caudal las aguas molientes derivadas del Saja-Sajuca. Desde ahí, su trazado vendría a corresponderse aproximadamente con el borde septentrional de las fincas particulares de ese tramo, hasta el punto en el que alcanzaba al Pulero, a la altura de Camarao. Con independencia de que captase igualmente sus aguas (o de que las salvase mediante acueducto, como en la actualidad), su trazado calcera abajo debía de coincidir con el de la actual, suministrando fuerza a los molinos del Pinganillo, del Alsar y de Abajo. Más problemas plantea la identificación de su final. Y ello obliga, a su vez, a hipotetizar acerca de las aguas con las que pudieran haber trabajado los molinos del barrio de Villanueva de la Peña con anterioridad a mediados del siglo XVIII, especialmente los del Cotero y de Solinde (y quizá en menor medida, el de La Bragada). La tendencia natural de las 
aguas de la calcera de Mazcuerras era (y es) a derramarse hacia la madre principal a través de un largo y meandriforme brazo del Saja que, en su primer tramo, recto, corre en disposición sur-norte. Por lo demás, y según venimos sosteniendo a propósito de Cos y Mazcuerras, cada uno de los dos núcleos de la margen derecha del Saja habría dispuesto de calcera propia con anterioridad a mediados del siglo XVIII. De ser también así en el caso del barrio de Villanueva (con concejo propio antes de esa fecha), ¿tomaría ésta sus aguas del Saja o, por el contrario, las tomaría del arroyo de la Fuente del Ojo (y tal vez también de algún manadero en las proximidades de Coíño)? Hoy en día, ni la documentación ni la información del terreno permiten responder con nada parecido a la certidumbre.

No es de descartar que, con posterioridad a mediados del siglo XVIII, y antes de ingresar en época contemporánea, la calcera hubiese experimentado algún retoque. Así parece sugerirlo un nuevo conflicto entre los concejos de ambas riberas a comienzos del XIX. Medio siglo antes, la capacidad de molienda de Ontoria y Vernejo, en la margen izquierda del Saja, era comparativamente muy inferior a la de los concejos de la margen derecha. Tenía, sí, cuatro molinos concejiles, pero eran ingenios pequeños, de una rueda, a excepción del de la Rotura, de dos. Sabemos también que eran pocos los meses del año que disponían de agua suficiente para moler. Así al menos cabe deducirlo de los flacos ingresos que sus arrendatarios pagaban al común a mediados del Setecientos: 30 reales anuales, en efecto, era lo que pagaban el de Arriba y el de Abajo, y muy poco más El Nuevo (60 reales); pero es que incluso el de la Rotura, con su mayor dotación de ruedas, pagaba tan sólo 132 reales, muy por debajo de los de equivalente capacidad instalada de Cos y de Mazcuerras ${ }^{17}$. Se entiende así que, ya con anterioridad a 1805 , el concejo hubiese establecido una presa sobre el Saja, seguramente a la altura del puente de Santa Lucía, aguas arriba de la calcera que ya conocemos a través del largo pleito del primer tercio del siglo XVII. Se entiende también que, al filo de 1807 , denunciase que los vecinos de Cos, seguramente inmersos en una sostenida competencia por remontar los azudes cada vez más atrás, «a la parte de arriba del puente de Santa Lucia han hecho de piedra y terrones una presa que atrabiesa todo el Rio Saja de manera que recojen en todas las aguas de este y las introducen en sus cauces de molinos con tanta abundan-

\footnotetext{
17 Archivo Histórico Provincial de Cantabria, Ensenada, Particulares, leg. 568. En casi todos los casos, los molinos de dos ruedas pagaban más de 200 reales anuales.
}

cia que les sobra para estos muchas aguas[,] las que se desperdician y derraman por muchas partes y quebrantadas $\sin$ que se puedan aprobechar por otros pueblos». Seguían:

Con dichos motibos y la sequedad del tiempo se halla mi citado concejo sin las aguas necesarias para su molino [así, en singular] que siempre se han recojido y deben recoger del mismo Rio Saja[,] y se halla tambien el mismo Rio en terminos que no pueden los becinos moler los granos tan necesarios para substentacion y alimento reduciendolos a harinas por lo que no tienen que moler.

Con arreglo seguramente a la vieja sentencia de 1632, alegaban que Cos no tenía derecho «a hacer la presa que han fabricado por todo el Rio», y pedían amparo a la justicia del valle para que obligase a Cos a reducirla a la mitad del lecho, lo que, al menos cautelarmente, parece haber ocurrido. Cos, pero también Mazcuerras (no en vano sabemos que, a estos efectos, la calcera unificada los unía ante un común adversario) declaraban sentirse despojados en sus privilegios y alegaban, no el supuesto derecho general de aguas en que se afirmaba la denuncia, sino la particularidad de que «tienen fundados sus molinos en sus respectivos alcabalatorios habiendo estado de inmemorial tiempo a esta parte en la quieta y pacifica y no interrumpida posesion de aprobechar las aguas del Rio de Saja con la que muelen y han molido continuamente aquellos artefactos». En consecuencia, pedían «cerrar la presa de Santa Lucia de la Carrera en el modo y forma que lo estaba antes de principarse esta instancia reintegrando a nuestros representados en la posesion [...] de tenerla asi cerrada para el aprovechamiento esclusibo de las aguas en que nos hallamos despojados». Es decir, pedían volver a prolongar la presa hasta la ribera izquierda, argumentando además (pero esto, por habitual y formulario, presenta un interés menor) que, «desde el largo tiempo de sus respectibas edades[,] hemos tenido la referida presa en el sitio de Santa Lucia para el recojimiento de las aguas con que deben moler los artefactos arineros de uno y otro pueblo», de Cos y de Mazcuerras. Afirmaban además su derecho a «atrabesar el rio según lo exija su poca o mucha necesidad» (la sequía, por ejemplo), lo que, de paso, sugiere que una presa permanente hasta la mitad del lecho pudiese verse suplementada con materiales más efímeros (precisamente la «piedra y terrones») hasta la ribera contraria. La alta instancia de Valladolid les daba finalmente la razón ${ }^{18}$. ¿Habrá sido en ese mo-

\footnotetext{
${ }^{18}$ Archivo de la Real Chancillería de Valladolid, Registro de Ejecutorias,
} $3797-4$ 


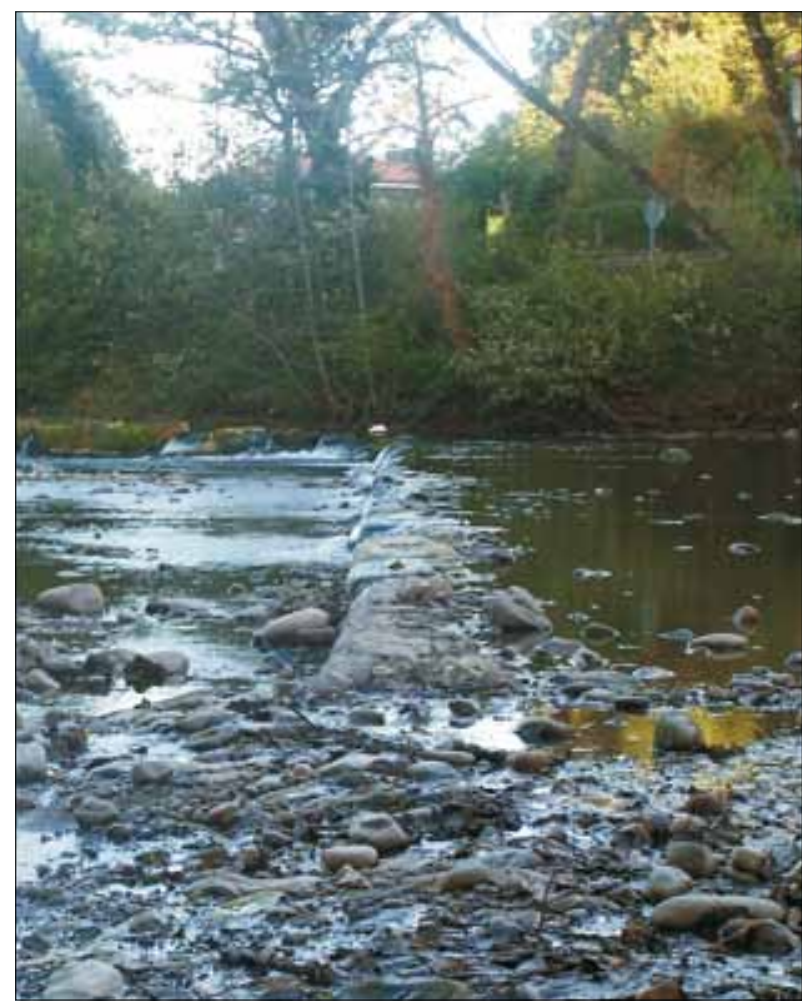

FIG. 8. El azud de la calcera unificada desde la ribera derecha del Saja, 2002; al fondo, a la izquierda, el inicio del canal de derivación. Fotografía de F. González Rebanal.

mento cuando la calcera retrasó su azud general? Todo parece indicar que sí, pues el azud actualmente existente presenta un despliegue hasta precisamente la mitad del lecho (Fig. 8), cumpliendo, por tanto, con la sentencia de varios siglos antes.

\section{BIBLIOGRAFÍA}

Ansola Fernández, A., y J. Sierra Álvarez (2007): $E l$ camino de las harinas en el corredor del Besaya: geografía, historia y patrimonio. Consejería de Medio Ambiente del Gobierno de Cantabria, Santander.

Delgado ViÑas, C. (2004): «Caracterización hidrológica y aprovechamiento de los recursos hídricos de los ríos de la vertiente cantábrica», en A. Gil Olcina (coord.): Alteración de los regímenes fluviales peninsulares. Fundación Cajamurcia, Murcia, pp. 653-683.

García Alonso, M. (1994): «Caminos y despoblados en el Alto Besaya». Trabajos de Arqueología en Cantabria. Monografías Arqueológicas, núm. 5, pp. 141150 .

García Codrón, J. C., y C. Garmendia Pedraja (2003): «El río y las aguas», en A. de Meer Lecha-Marzo (ed.): Cabezón de la Sal: tradición, cambio y futuro. Universidad de Cantabria, Santander, pp. 45-71.

Hernández-Pacheco, F. (1941): «Estudio geológico y fisiográfico del valle alto y medio del río Besaya (Santander)». Anales del Museo Nacional de Ciencias Naturales.

Iglesias Gil, M., y J. A. MuñIz Castro (1992): Las comunicaciones en la Cantabria romana. Universidad de Cantabria/Librería Estudio, Santander.

UREÑA, J. M. (ed.) (1999): Ordenación y protección ambiental de ríos en Europa. Universidad de Cantabria, Santander.

VARA Recio, A. (1995): Acerca de la organización de un espacio agrario tradicional: usos y costumbres en Valle de Cabezón de la Sal, 1500-1820. Comité de Organización del Festival de Cabuérniga, Santander. 